\title{
REVIEWS.
}

\section{SEX EFFICIENCY THROUGH EXERCISES}

\author{
By Th. H. VAN de Velde, M.D.
}

25/- net. W. Heinemann (Medical Books) Ltd., London.

pp. $163 ; 480$ cinematograph illustrations.

This book is a sequel to the author's Trilogy - "Ideal Marriage ", etc. It aims at providing a guide for women and those who help them, as doctors, midwives, and gymnastic instructresses, in the full evolution and utilization of the feminine sexual capacities and faculties. The author considers that these are generally quite inadequate in practice; they should include active participation in the act of sexual congress and voluntary muscular action to assist the act of birth. "At present women generally suffer both of these great genital experiences passively." To correct this the author has worked out a series of pelvic gymnastics. He divides them into three groups adapted to assist in the act of sexual congress, in the muscular aid of confine- ment, and the rapid and full restoration of tone and strength to the pelvic musculature in the puerperium. There are also a set of exercises for the restoration of the beauty of the bust after confinement.

The author admits that the exercises will have to be taught by sympathetic instructresses to avoid the possibility of too great suggestion, and the offence of modesty.

The book is well printed: many of the illustrations are from photographs taken in beautiful surroundings; some of the exercises are depicted in a series of cinematographic "flickers". The book, if it falls into the right hands, will doubtless be of great value.

\section{DISEASES OF INFANCY AND CHILDHOOD.}

Edited by Prof. Leonard Parsons and Prof. Seymour Barling. Oxford University Press. Henry Milford. Two volumes : Net price 4 Guineas. pp. 1798.

This book is one of the most delightful medical text books that it has been our pleasure to read. It is ambitious in its scope, and aims at telling us all there is to be told about the upbringing of normal children as well as the diseases that children are heir to. How well it has succeeded can only be gauged by examining the book critically. It is written by the two editors with the aid of 44 collaborators drawn from Great Britain and America: each of these is writing a section of which he is an acknowledged authority. The result is that we have one of the most complete accounts of the diseases of children which has been written in the English language. It is impossible to sit down and read a book of this dimension from cover to cover, but if passages are taken in which we are specially interested, we are liable to burn the candle far into the night.
Every aspect of children's diseases is dealt with, including the surgical aspect. The descriptions are clear and are enriched by occasional case notes, 230 figures, 59 full page $\mathrm{X}$-ray prints and 8 coloured plates.

It is invidious to criticise a book of such all round merit as this, but it does seem that perhaps the amount of space allotted to rickets ( 80 pages) could be shortened by condensing the pathology. In later editions, of which there are bound to be many, it will be possible to discuss the ketogenic treatment of pyelitis in greater detail. Also the excellent index would be reached more readily if placed after the $\mathrm{X}$-ray diagrams.

We cannot be too loud in our praise of this book which must be in the hands of everyone who is interested in children's diseases. Although its price is high at 4 guineas, rarely was such a sum better spent. 